\title{
La antigua Roma en la narrativa de Rubén Darío
}

\author{
Rosa PELLICER \\ Universidad de Zaragoza \\ rosapel@unizar.es
}

\begin{abstract}
RESUMEN
En el presente artículo se consideran los cuentos ("Febea", "Respecto a Horacio. Papiro" y "La fiesta de Roma") y la novela inconclusa El hombre de oro que tienen como escenario la Roma del Imperio. Además de plantear el tema del artista y el mundo, estas narraciones son "recreaciones arqueológicas", que tienen como punto de partida otros textos, que se tratan de identificar. Su análisis corrobora su inserción en una moda literaria, el relato histórico, pero también su permanente interés por la tradición clásica.
\end{abstract}

Palabras clave: Rubén Darío, cuentos, Antigua Roma, reescritura.

\section{The ancient Rome in Rubén Darío’s fiction}

\begin{abstract}
In this article the stories ("Febea, "Respecto a Horacio. Papiro" y "La fiesta de Roma") are taken into account, and the unfinished novel El hombre de oro which take place in the Roman Empire era. Aside from setting the artist's topic and world, this narrations are "archeological recreations", which have other texts as starting points, which are tried to be identified. Their analysis backs up their introduction in a literary trend, the historical fiction, but also their permanent interest in classic tradition.
\end{abstract}

Key words: Rubén Darío, stories, ancient Rome, rewriting.

Rubén Darío manifestó en numerosas ocasiones su admiración y atracción por el mundo de la Antigüedad griega y latina, y desde muy pronto asumió y recreó temas y motivos clásicos en su obra, que contribuyeron a ese "clasicismo modernista" del que hablara José Enrique Rodó y que llevaron a escribir a Arturo Marasso las siguientes palabras: "Y supo de todas las escuelas, de todos los poetas, de pintores y de músicos, de Grecia, de Roma, de la ciencia moderna y antigua, y creó esa quinta esencia de que habla Valera, ese 'bronce corintio' y ese 'mármol de Jonia'". 
(Marasso 1954: 1) $)^{1}$. En varias ocasiones Darío señaló que para conseguir la renovación en las letras era necesaria la vuelta a los clásicos. En Historia de mis libros, al referirse a las "Recreaciones arqueológicas" de Prosas profanas, escribe:

Son ecos y maneras de épocas pasadas, y una demostración, para los desconcertados y engañados contrarios, de que, para realizar la obra de reforma de modernidad que emprendiera, he necesitado anteriores estudios de clásicos y primitivos (Darío 1917:195).

Por su parte, Alejandro Sux en los recuerdos de su amistad con Darío enumera alguna de sus ideas fijas; entre ellas se encuentra la siguiente: "Occidente es esencialmente pagano; el Cristianismo se paganizó en los países latinos, únicos con derecho a llamarse occidentales, nietos de Grecia e hijos de Roma, cunas del paganismo" (Sux 1946: 314). Esta idea expresa el intento de aunar cristianismo y paganismo y se opone a otras afirmaciones bien conocidas. Solo un ejemplo. En la Historia de mis libros, al referirse a Cantos de vida y esperanza, Rubén Darío explica que en el prólogo y en el primer poema habla de "la simiente del catolicismo contrapuesta a un tempestuoso instinto pagano" (Darío 1917: 205).

En la década de los noventa Rubén Darío escribió tres cuentos "Febea" (1891), "Respecto a Horacio. Papiro" (1893), "La fiesta de Roma" (1898), y una novela inconclusa de carácter histórico cuya acción se desarrolla en la antigua Roma: El hombre de oro $(1897)^{2}$. Como en el caso de las evocaciones de Grecia, estos textos son una suerte de "recreaciones arqueológicas", que responden tanto a la predilección por épocas pasadas, íntimamente relacionada con el apogeo de la historia como disciplina en la última década del siglo XIX, cuanto a la admiración por la cultura y la literatura grecolatinas a través de la mediación francesa ${ }^{3}$. Ahora

${ }^{1}$ Para este asunto, véase, entre otros, el artículo de José Carlos Rovira (2009).

${ }^{2}$ Carlos Mata Induráin, dentro de la clasificación de los cuentos de Darío, incluye en el apartado "Cuentos ambientados en la antigüedad pagana" los cuentos "Las siete bastardas de Apolo" y "El sátiro y el centauro. Palimpsesto". He excluido estos textos debido a su carácter mitológico, aunque el último plantee también la oposición paganismo/cristianismo. Las relaciones entre paganismo y cristianismo en "La fiesta de Roma" y El hombre oro han sido estudiadas en detalle por Marcos Ruiz Sánchez (1999), a cuyo estudio remito. Significativamente, Mary Avila C.S.J. (1959) en su artículo sobre el cristianismo en los cuentos de Darío no menciona "La fiesta de Roma".

${ }^{3}$ Enrique Marini-Palmieri, al referirse a los cuentos modernistas hispanoamericanos que evocan épocas de la Antigüedad, señala que los escritores ante la envejecida tradición española y ante la cultura indígena detenida en su evolución descubrieron la tradición clásica, al mismo tiempo que los europeos también insatisfechos con su propia cultura: "Entonces los modernistas se apartaron de ciertos escritores que reinaban en ese 
bien, hay que distinguir entre la narrativa de inspiración helenizante y la de inspiración latinizante, como advierte Marie-France David de Palacio:

le néo-hellénismo recherche l'éloignement du temps présent, ce temps de laideur et d'hypocrisie. Mais les écrivans qui se réclament de la Décadence romaine, ces Décadents souvent auto-proclamés, se retrouvent au contraire dans des lieus communs de la Décadence révélateurs de la modernité. Ainsi, le spleen de Messaline, Néron ou Héliogabale, est résolument baudelairien et moderne (David de Palacio 2005: 5).

El período privilegiado en el fin del siglo XIX es la Roma imperial, no la republicana, que sirve a los autores para revindicar la decadencia, el desorden, la extravagancia. En esta narrativa encontramos una serie de lugares comunes del decadentismo (la crueldad, el erotismo, el gusto por las joyas); así como los espacios del circo, de las villas romanas; y las figuras históricas privilegiadas y hostiles a las masas (Nerón, Popea, Calígula o Tiberio). A esto hay que añadir que los modelos, como señaló Highet, despliegan dos tipos de argumentos: "el cristianismo significa represión: el paganismo significa libertad", y "el cristianismo es tímido y débil; el paganismo fuerte e intenso". A diferencia las novelas y cuentos que recrean la Atenas del siglo $\mathrm{V}$, donde desaparece el conflicto del protagonista con la sociedad, puesto que lo que se celebra es la armonía pagana, los escritores latinizantes utilizan esta época para referirse a la suya. En el caso de Darío, El hombre de oro y los cuentos romanos vuelven a plantear, entre otros, el tema del artista y el mundo.

En este tipo de narraciones los modelos son las novelas de Wiseman, France, Swinkiewicz, Wallace, y algunos cuentos de Gautier, France o Richepin, entre muchos otros. Fabiola, o la iglesia de las catacumbas (1854) de Nicholas Wiseman, Thaïs (1890) de Anatole France, Ben-Hur (1890) de Lewis Wallace o Quo vadis? (1896) de Henryk Swinkiewicz, pero también relatos anteriores como "Arria Marcella, souvenir de Pompéi” (1852) de Téophile Gautier, La Coupe

momento...Fuéronse hacia Homero, Hesíodo, Orfeo, Apolo y compañía. Como mucho jóvenes poetas europeos en ese entonces. Esa era una manera de ser modernos entonces" (Marini-Palmieri 1989: 26).

${ }^{4}$ Añade Gilbert Highet: "En particular, varios escritores del siglo XIX detestaban el cristianismo a causa de las restricciones que impone sobre la libertad sexual, y admiraban el paganismo grecorromano porque (según creían) el amor en Grecia era libre y no tenía que sonrojarse". Respecto a las novelas que describen la lucha entre los ideales paganos y los cristianos del Imperio romano, "divulgaron la idea de que Roma cayó por ser un imperio pagano inmoral, creencia muy difundida ahora. Pero pasan por alto el hecho de que tanto el Imperio de Occidente como el de Oriente cayeron mucho tiempo después de haber abrazado oficialmente el cristianismo" (Highet 1978: 246 y 254). 
d'Hercule (papyrus pompéien) (1878) y "Cécube de l'an 792" (1877) de Gustave Toudouze, "Myrrha, vierge et martyre" de Jules Lemaitre; el célebre relato de France "El procurador de Judea" (1891); Contes de la décadence romaine (1898) de Jean Richepin, a quien Darío incluye entre "los raros", o las Vidas imaginarias (1896) de Marcel Schwob. No cabe duda de que Rubén Darío conocía buena parte de estos textos, algunos de los cuales tuvieron un gran éxito, ya que los menciona, por ejemplo, en Peregrinaciones. El 8 de octubre de 1900 apunta: "[...] llego ante la iglesita del Quo Vadis, cuya inscripción me parece de pronto -perdonadme mi ingenuidad- la réclame de una casa editorial para la notable, compacta y demasiado resonante novela del polaco Swienkiewicz" (Darío 2003: 248-249). Ante la decepción que le produce el mercantilismo de los frailes durante la visita a las catacumbas, Darío exclama: “iMe quedo con Fabiola!” (Darío 2003: 248-249 y 250). En otro orden de cosas, Ignacio Arellano (2013) apunta que una de las razones por las que Darío no terminó su novela El hombre de oro pudo ser el abrumador éxito de Quo Vadis?, que hizo que abandonara su proyecto. A esto se unió, como señala Juan Loveluck (1967) la repentina interrupción de la revista $L a$ Biblioteca, dirigida por Paul Groussac, donde se publicaba la novela ${ }^{5}$.

Como en el caso de las novelas históricas, en los relatos historia y arqueología mantienen un difícil equilibrio, ya que debe de predominar la acción sobre la descripción ${ }^{6}$. Lo arqueológico aparece en los cuentos en las referencias al mundo en el que se insertan. Por otra parte, los textos de Darío son variantes o tienen su punto

${ }^{5}$ El 19 de noviembre de 1900, en una carta desde Valparaíso sin firma, pero casi con seguridad de Eduardo Poirier, este le pide un prólogo para su traducción -seguramente del francés- de la obra de Swinkiewicz:

"Mi querido Rubén:

Confirmo las varias cartas que le he remitido a París (Poste Restante). Mucho le agradecería que al recibir esas cartas y los dos ejemplares de Quo vadis que le he remitido quisiera favorecerme con el juicio pedido. La casa de Maucci ha hecho una $2^{\circ}$ edición dela obra con mi versión, y en la $3^{\circ}$, que próximamente saldrá, se desea que figure el artículo de V. Yo en esto persigo solo esos fugaces humos de gloria, único premio del pobre escritor: la casa Maucci se lleva el provecho" (Poirier 1900).

${ }^{6} \mathrm{En}$ su estudio fundamental sobre la novela histórica Amado Alonso distingue entre historia y arqueología: "Vamos a llamar historia a la sucesión de acciones que en su eslabonamiento forman una figura móvil con unidad de sentido; y vamos a llamar arqueología al estudio de un estado social y cultural con todos sus particularismos de época y de país, y cuyo sentido y coherencia no está en la sucesión sino en la coexistencia y en la recíproca condicionalidad de sus elementos: instituciones, costumbres, técnicas, viviendas, indumentaria, alimentación, instrumental, etc. También le interesa a la arqueología el hacer humano, pero no lo individualizable, sino lo despersonalizado, lo genérico al hombre de una época en un país, de modo que, aunque es un hacer que transcurre, se puede considerar como un estado por lo que tiene de habitual y genérico. Se le suele llamar 'el espíritu de una época"" (Alonso 1984:9). 
de partida en otros textos, como se señala en los paratextos en los que figuran palabras como "papiro" o "palimpsesto".

Este el caso de "Febea", uno de los relatos más conocidos y menos considerados por los estudiosos de los cuentos darianos. En su primera edición, este breve relato no se presenta como una traducción falsa de un texto antiguo también falso, como "Historia prodigiosa de la princesa Psiquia, según se halla escrita por Liborio, monje, en un códice de la abadía de San Hermancio, en Iliria, sino como un "palimpsesto"'. Este cuento apareció por vez primera en 1891 en La Prensa Libre de Costa Rica junto a "El árbol de rey David" bajo el título de "cuentos nuevos", como señala Raimundo Lida. Es significativo que en una de sus numerosas ediciones, la de El Porvenir de Centro-América (San Salvador, 15 de marzo de 1896) a los cuentos mencionados, a los que se les suma "La muerte Salomé", se les denomine "palimpsestos". Si en este y en "El árbol del rey David" el hipotexto es evidente, el caso de "Febea" es más complejo. Febea, la pantera de Nerón, se niega a devorar a la joven cristiana Leticia, que se ha mostrado insensible al canto del emperador, porque sus "dáctilos y pirriquios te [sic] han resultado detestables" (Darío 1983: 226) ${ }^{7}$. El Libro VI de las Vidas de los doce césares, de Suetonio es la fuente principal de los narradores que recrean, más o menos imaginativamente, la imagen y la vida de Nerón. Darío presenta al "siniestro semidiós" como "un andrógino corrompido" con una especial inclinación a la poesía. Las referencias a la existencia de un felino en relación con el emperador son escasas. Suetonio dice que Nerón:

había proyectado incluso imitar también las hazañas de Hércules; y se había adiestrado a un león, según dicen, para que él, totalmente desnudo, a la vista del pueblo lo aplastara con la maza o lo estrangulara entre sus brazos en la arena del anfiteatro (Suetonio 1992: 183).

Por su parte Séneca alude a que un tigre en lugar de descuartizar en la arena a Nerón, lo besó ${ }^{8}$. Tal vez estas escasas alusiones a un león o a un tigre más o menos domesticados le bastaron a Alejandro Dumas para que la tigresa Phoebé sea la fiel compañera de Nerón en la novela Acté (1839), cuya fuente principal es Suetonio. En esta novela histórica la joven corintia, que estuvo al lado del emperador hasta su muerte, conoce a Pablo, se convierte al cristianismo, y decide salir de las catacumbas para interceder por los cristianos. En ese momento se anuncia la boda de Nerón con Sabina/Esporus, y Acté, presa de los celos, va a la Casa Dorada con la intención de matar al emperador. La llevan a prisión junto con Silas y Pablo, y

7 Todas las citas de los cuentos remiten a esta edición.

8 "Seneca (Ep. 85.41) refers to a tiger in the rule of Nero that was trained to performer tricks with its keeper in the arena; apparently the animal allowed the keeper to kiss it" (Hawtree 2011: 101). 
posteriormente en los juegos del circo la atan a un árbol para que la devore una fiera:

la tigresse se coucha, douce et câline comme une gazelle, puossant des petits cries de joie, et l'échant les pieds de son ancienne maitresse: à ces caresses inattendues Acté surprise rouvrit les yeux et reconnut Phoebé, la favorite de Néron (Dumas 1854: 42).

Una versión resumida de la novela de Dumas apareció de forma anónima bajo el título "Febea (Tigre de Nerón)", en Managua en el Diario de la Capital el 16 y el 17 de mayo de 1891. Este relato ya había sido publicado por José de Castro y Serrano en 1858 en su libro Animales célebres de todos los tiempos y de todos los países, lo que confirma la difusión de Acté en el mundo hispánico 9 . Posteriormente, en Quo vadis? la esclava Ligia, convertida al cristianismo por san Pablo, también es condenada a ser devorada por la fieras y es defendida por la tigresa Febea. La única variante es que Swinkiewicz sustituye el árbol al que está atada Actea por un poste, en un decorado de venatio ${ }^{10}$. La relación, feminizada, con la historia de Androcles es evidente, y forma parte de tradición del "león reverente". Como señala Miguel Garci-Gómez, las actas de los mártires refieren muchos de estos ejemplos en los que el cristiano, echado a los leones, es reverenciado por estos ${ }^{11}$.

El primer cambio significativo que introduce Darío en esta historia es convertir el león o tigre en pantera, ya que esta simboliza, por lo menos desde Dante, la voluptuosidad y la lujuria. Leticia, la joven cristiana a la que lleva Nerón a su presencia, tiene quince años y "el cuerpo de efebo que estuviese para transformarse en mujer", se muestra insensible al canto "erótico y bien rimado según las reglas de su maestro Séneca" (226), que el poderoso poeta entona para seducirla. Su fracaso como poeta desata la violencia al decidir que el animal se cobre su venganza. En este caso, a diferencia de otros relatos, no se plantea el tema del artista en oposición al mundo que lo rodea, sino el del poeta mediocre incapaz de asumir su medianía ${ }^{12}$.

${ }^{10}$ En el célebre cuadro Nerón en la bahía (1900) de Jan Stkya, el emperador también aparece acompañado de un tigre.

11 "Casi todas estas narraciones siguen un patrón común, en que se observan las siguientes características generales: desobediencia (enemistad) del cristiano con el emperador, que le ordena sacrificar a los dioses; aspecto aterrador del león; actitud reverente del animal hacia el santo; asombro de los espectadores, interpretación del hecho como testimonio del carisma (poder de Dios)" (Garci-Gómez).

12 Tácito, al hablar de la costumbre que tenía Nerón de rodearse de algunas personas capaces de versificar, pero no notorios poetas, juzga sus versos: "Después de cenar se reunían y ensartaban los versos que él llevaba o improvisaba allí mismo, y completaban las 
Por otra parte, en este cuento, a pesar de aparecer una cristiana y un pagano, no se reflexiona sobre paganismo y cristianismo.

"Respecto a Horacio. Papiro" comparte con "Febea" su carácter de reescritura. Se inicia con puntos suspensivos, de modo que parece un fragmento ajeno, incompleto, que se transcribe. Hasta el penúltimo párrafo no conocemos la identidad del narrador, Lucio Galo y el carácter del texto. Se trata de la confesión, escrita cinco años después de su intento de matar a Horacio a causa de que este animaba el amor de Jantias por su esclava Filis de la que el fallido asesino estaba también enamorado. Galo taló un árbol de la arboleda de la finca de Horacio por la que este solía pasear, con la esperanza de que al empujarlo cayera sobre él y lo matara. La caída de un árbol motivó la escritura de la oda 13 del Libro II, con cuyo primer verso ("Ille nefasto te posuit die") termina el relato. Estamos, pues, ante un texto que imaginativamente explica el accidente, que no sería tal, que casi acabó con la vida del poeta, y que dio lugar a escritura de la oda citada en la que se maldice al árbol y al que lo plantó. Este episodio volverá a ser recordado en los versos de la segunda estrofa de la oda 8 del tercer libro, donde un año después el poeta celebra el haber escapado del peligro ${ }^{13}$.

La mayor parte de este cuento corresponde a la descripción de un banquete, tema obligado en las novelas históricas que recrean el mundo romano y que también aparece en los relatos de este tipo. En este caso, Horacio, el anfitrión, recibe a Mecenas en su quinta y tras la cena, recita sus propios versos: "Desgrana dáctilos como uvas; deshoja espondeos como rosas" $(292)^{14}$. A diferencia de El hombre de oro, en este cuento la relación poeta-mundo solo se manifiesta de forma muy tangencial, ya que Mecenas es presentado como un buen amigo, que, además, admira a su protegido y lo visita en la finca que le regaló cerca de las montañas Sabinas. En este relato, el desprecio al poeta se concentra en el "delicado y

palabras que profería según le venían; esto lo denuncia el estilo mismo de sus poemas, que no fluye con fuerza, inspiración ni tono uniforme" (Tácito 1980: 169-170).

13 "voveram dulcis epulas et álbum/Libero caprum prope funeratus/arboris ictu" (Horacio 1990: 262).

${ }^{14}$ Lucio Galo elogia un ánfora, cuya descripción podría tener su antecedente en el poema "El ánfora" (1889), que Darío no recogió en Prosas profanas. Leemos en el relato: "alrededor de la panza tiene figurada una viña copiosa; bajo la viña el gran Baco en su florida juventud y rodeado de ménades y de tigres, cuyas fauces se humedecen con la dulzura que les impone la majestad del numen; cerca está la figura de Sileno, que ríe viendo danzar un coro de faunos, los cuales levantan sobre sus cabezas sortijas de caireles y pámpanos recién cortados" (292-293). Y en el poema: “Grabó en ella un artífice, con su buril divino,/junto a una viña virgen, a Baco y su esplendor,/y a Pan, que enseña danzas, el rostro purpurino,/a cabras y pastores bajo un cítiso en flor" (Darío 1983: 180). 
equívoco" Ligurino, que mantiene una actitud arrogante y desdeñosa ante los elogios que Mecenas dirige a Horacio: "Reíase no muy discretamente de las palabras pronunciadas por el amigo imperial y, mirando de soslayo, satirizaba al anfitrión" (292).

"Respecto a Horacio. Papiro" da un paso adelante en la escritura "arqueológica". En "Febea" Darío se limita a citar a Ovidio, y a hablar de "dáctilos y pirriquios". Nerón es una figura histórica familiar a todos los lectores, en cambio ahora aparece Mecenas algo menos conocido, al lado de personajes reales y ficticios que aparecen en las odas horacianas: los poetas y gramáticos Albio Tíbulo, Aristio Fusco, Crispo Salustio, Publio Quintilio Varo o pertenecientes a la sociedad romana como Elio Lamia, que podemos recordar es uno de los protagonistas de El procurador de Judea de Anatole France, Jantias el Foceo, al lado de Ligurino o Lidia. A los que habría que añadir los de Telefo, Mirtala, Lisis, y las menciones a Catón, Arquesilao, Epicuro, Anacreonte, o a Pegaso, Baco, Sileno, entre otras. Demasiados nombres para un cuento que apenas ocupa tres páginas. Además, el relato no acaba de cobrar un sentido completo si el lector no ha leído, y recuerda, la oda de Horacio que da pie a su escritura y con cuyo primer verso, como ya se ha mencionado, citado en latín, termina ${ }^{15}$. Estamos ante el escritor erudito que hace gala de su conocimiento libresco, más o menos profundo, ante el culto lector para el que la lectura se convierte en un desciframiento.

El poeta Lucio Varo y san Pablo son los únicos personajes de "La fiesta de Roma", que más que una narración es un canto a la grandeza romana. Es de sobra conocido que este cuento se ha considerado como un posible capítulo de El hombre de oro, ya que se publicó un año después de aparecer los tres que forman parte de la novela. Sin embargo, no puede considerarse una continuación de estos, como mucho se trataría de algún capítulo intermedio o, mejor, de una reescritura del tercer capítulo de la novela, ya que, como se ha señalado repetidamente, el "secular Carmen" (345) que entona el poeta en alabanza de la grandeza romana figuraba en prosa en dicho capítulo. Lucio Varo y san Pablo se encuentran en una barca en el Tíber y, a la vista de la ciudad, el poeta repasa su biografía espiritual, la pérdida de la fe en los antiguos dioses y la creencia inquebrantable en "Roma la Buena Diosa", que en un futuro extenderá su poder ante mundos nuevos. El largo parlamento de Varo solo se ve interrumpido en dos ocasiones por Pablo: la primera, para comentar que su duda "-Era el hambre de Dios" (344), y al final cuando paganismo y cristianismo se muestran inconciliables:

15 Sobre las citas de Horacio en Darío, Dolores Ackel Fiore señala brevemente a propósito de "Respecto a Horacio": "Darío's quotations are certainly used with varying degrees of sublety; he seems to have strained a bit to allow himself the opportunity of inserting these lines, as appropiate as they may be in this instance" (Ackel Fiore 1963: 38). 
Pablo volvió a interrumpir:

-Yo anuncio al Dios del triunfo venidero.

Y Varo:

-¡Roma será inmortal!... (346)

El nombre y el personaje de Lucio Varo tal vez lo tomó Darío de Lucio Vario Rufo, poeta épico y trágico romano que fue amigo de Virgilio y de Horacio, quien lo menciona, entre otros lugares, en la Oda 16 del libro primero, "Ad Agrippam" ${ }^{16}$. Pero, dejando de lado la cuestión onomástica, cuyo mínimo cambio sería obligado para no cometer un anacronismo, quizá no sea demasiado arriesgado suponer que Darío pudo conocer el cuento de Clarín "Vario", publicado por primera vez en 1894 e incorporado luego a Cuentos morales (1896). Vario en su viaje por mar de Roma a Grecia reflexiona sobre el papel del escritor, el sentido de la vida y de la muerte, los dioses, la inmortalidad del poeta, como señala Carolyn Richmond (1990: 17.18). El Varo de Darío y el Vario de Clarín, además de su condición de poetas, comparten, entre otras cosas, su escepticismo. Solo un ejemplo. Dice Varo: "Todos los dioses fueron ocultándose a mi deseo, o esquivándose a mi fatiga" (344), y "No creía Vario en la mitología, que llenaba de nombres y de imágenes sus versos; pero si no como filósofo, como artista, en su corazón y en su fantasía, era pagano" (Alas, 2012: 211). Por otra parte, en el cuento de Clarín y el capítulo tercero de El hombre de oro aparece el motivo de las sirenas, con cuyo encanto carnal y sus cantos hechiceros llaman a la muerte.

En esta novela inconclusa, que se desarrolla en la época de Tiberio, se introduce el tópico dariano de la distancia que separa al artista del que ejerce el mecenazgo al hablar de la relación entre Horacio y su protector ${ }^{17}$. El capítulo segundo está prácticamente dedicado, como el cuento "Respecto a Horacio", al banquete que ofrece Quinto Flavio Polión en su lujosa villa, descrita con sumo detalle, a Axio, un joven centurión; a Acrino, un joven efebo; al poeta Lucio Varo, protagonista también de "La fiesta de Roma"; y a su vecino El Hombre de Oro, que resulta ser Judas Iscariote, quien evidentemente no se suicidó después de traicionar a Jesús. Dado que estos personajes poseen "la pasión dichosa de las artes y las letras" (Darío 1995: 15$)^{18}$, su conversación es elevada y gira en torno a temas frecuentados por

16 Lucio Varo, señala Ernst Bickel, “era la personalidad más relevante en el círculo poético de Mecenas. Todavía que la Medea de Ovidio, era tenida su tragedia Thyestes como obra maestra de la retórica romana" (Bickel 1982: 484). Además Quintiliano lo define como "epicureus Cesaris amicus" (Forcellini 1965:752).

${ }^{17}$ El estudio de Juan Loveluck (1967) sobre los capítulos conservados de esta novela continúa siendo imprescindible. Para la relación de El hombre de oro con las demás novelas de Darío véase los artículos de Dolores Philipps-López (1998) y de Jorge Eduardo Arellano (2013).

${ }^{18}$ Todos los fragmentos citados de El hombre de oro corresponden a esta edición. 
Darío: el placer como única aspiración el hombre, el canto a la vida retirada, la juventud como la única época feliz y, como en "El rey burgués", Emelina o El oro de Mallorca, la relación entre el artista y el dinero. Quinto Flavio afirma que su padre le contó cómo Horacio se quejó amargamente de que Mecenas "le puso en el pescuezo un yugo de oro" (23). Además de verse obligado a celebrar a su protector, que no comprendía su alma:

se empequeñecía cuanto podía, el poeta, y, por tanto, aristócrata y príncipe de nacimiento, a quien habrían sido pocos los palacios de Darío y los esplendores de Ecbatana, y decía contentarse con este modesto retiro y serle más grata su existencia mediana que todos los triunfos y tesoros (24).

Cabe recordar que con tono humorístico un joven Darío en "La profecía de Horacio" finge que se exhumó un manuscrito de Horacio, traducido por Renan, en el que vaticinaba el nacimiento de un poeta en Nicaragua que pediría dinero a su amigo, el dr. Jerónimo Ramírez. Antes de la "profecía", el poema evoca la relación de Horacio con Augusto y Mecenas, que lo colmó de riquezas, aunque todavía no aparece el conflicto entre el artista y su protector. El pago del poeta a su generosidad fue otorgarle la inmortalidad en sus versos ${ }^{19}$.

La incomprensión del artista tanto por los poseedores de la riqueza y del poder como por el vulgo aparece también en las palabras de Lucio Varo, que se niega a recitar sus propios versos en público, al igual que hiciera Horacio,-incluso ante sus amigos, ya que

En general, junto a los compañeros inteligentes, suelen encontrarse en los festines bien epilados farsantes, obtusos mundanos que se dan aires de conocedores [...] $\mathrm{y}$ os felicitan ineptamente por lo que no han comprendido [...]; otros os burlan en su interior y os miran con lástima por vuestros pensamientos nefebiláticos; otros, los peores, los mediocres, vulgares aretálogos, os envidian (38).

Así que deciden recitar versos de Horacio en latín, fundamentalmente la oda 9 del libro $\mathrm{III}^{20}$. En este caso quien se muestra insensible a la lectura es el Hombre Amarillo, que se queda dormido. La inserción de los fragmentos en latín obedece a un designio estético. La irrupción de los versos produce una discontinuidad en el texto al desgajarse del contexto inmediato, al tiempo que produce extrañamiento $\mathrm{y}$,

19 "Tanto, que Horacio en muy buenas/ odas y epístolas largas,/ dándole versos por cargas,/ inmortalizó a Mecenas" (Darío 1941: 146).

${ }^{20}$ Arturo Marasso habla de la tradición horaciana que encontró Darío en Buenos Aires. Tras El hombre de oro, "Lo cita en lugares difíciles con cierta enigmática ciencia. Lo cita como buen catador de frugales placeres de la mesa. En su vida de trabajador Rubén habrá descansado en una palabra de Horario" (Marasso 1954: 384). 
como hemos mencionado, convierte a la lectura en una especie de enigma que hay que descifrar. Las inserciones en latín, en una tipología diferente, contribuyen a la puesta en valor del fragmento. Unidas a la presencia de voces rescatadas y suntuosas y a los cuadros mitológicos, a la vez que pueden ser consideradas como una tentativa poética, sacrifican la acción al poder de la palabra y toman distancia respecto a la narración ${ }^{21}$.

Los paisajes culturales exhibidos en estos cuentos son los mismos de la poesía de Darío de estos años. Como señala Loveluck a propósito de El hombre de oro: "Y [el lector] conviene en que en ellos no ha logrado entrar la vida, a pesar del esfuerzo virtuosista de su creador: no se respira más que el frío aire del museo exquisito, pero detenido en otro tiempo" (Loveluck 1967: 57). Estas recreaciones arqueológicas son, desde luego, un buen ejemplo del taller del artista, un tributo a una moda literaria, pero también son huellas del permanente interés de Darío por la tradición clásica, que va más allá del componente mitológico, resumido en los siguientes versos de "Retorno":

¡Oh cuantas veces, cuántas oí los sones

de las sirenas líricas en los clásicos mares! (Darío 1941: 755)

\section{BIBLIOGRAFÍA}

ACKEL Fiore, Dolores.

1963 Rubén Dario in Search of Inspiration. New York: Las Americas Publishing.

ALAS, Leopoldo "Clarín".

2012 Cuentos morales. Jean-François Botrel (ed.). Madrid: Cátedra. Alonso, Amado.

1984 Ensayo sobre la novela histórica. El modernismo en "La gloria de don Ramiro". Madrid: Gredos [1942].

ARELLANO, Ignacio.

2013 "Darío: El novelista que intentó ser", Anales de Literatura Hispanoamericana, 42, pp. 135-149.

${ }^{21}$ Este trabajo de orfebrería, y arqueología, se corresponde con los tempranos y famosos consejos de Rubén Darío expuestos en su ensayo "Catulle Mendès. Parnasianos y decadentes" (1888): "Juntar la grandeza o los esplendores de una idea en el cerco burilado de una buena combinación de letras; lograr no escribir como los papagayos hablan, sino hablar como las águilas callan; tener luz y color en un engarce, aprisionar el secreto de la música en la trampa de plata de la retórica, hacer rosas artificiales que huelen a primavera, he ahí el misterio. Y para eso, nada de burgueses literarios, ni de frases de cartón" (Darío 1989: 31-32). 
AVILA, Mary.

1959 "Principios cristianos en los cuentos de Rubén Darío", Revista Iberoamericana, 24 (47), pp. 29.39.

BICKEL, Ernst.

1982 Historia de la literatura romana. José $\mathrm{M}^{\mathrm{a}}$ Díaz-Regañón (trad.). Madrid: Gredos.

DARÍO, Rubén.

1917 El viaje a Nicaragua. Historia de mis libros. Madrid: Mundo Latino.

http://rubendariodigital.magazinemodernista.com/descargas/Ruben Dario17.pdf [consulta: 10/05/2016]

1941 Obras poéticas completas. Madrid: Aguilar.

1983 Cuentos completos. Ernesto Mejía Sánchez (ed.) y Raimundo Lida (estudio preliminar). México: FCE.

1989 El modernismo y otros ensayos. Iris M. Zavala (ed.). Madrid: Alianza.

1995 El hombre de oro y otros relatos. Madrid: Aguilar.

2003 Peregrinaciones. Santa Fe (Argentina): El Cid Editor.

DAVID PALACIO, Marie-France.

2005 Reviviscences romaines. La latinité au miroir de l'esprit fin-desiècle. Berne: Peter Lang.

DUMAS, Alexandre.

1854 Acté, en Oeuvres complètes de M. Alexandre Dumas. Paris: Michel Lévy Fière.

http:/gallica.bnf.fr/ark:/12148/bpt6k61483640.r=Acté\%20Dumas\% 20Acté?rk=21459;2 [consulta: 14/05/2016]

ForCELLINI, Aegidio.

1965 Lexicon totius latinitatis. VI. Onomasticon J-Z. Arnaldus Forni Exudebat Bonomine y Gregoriana Edente Patavii.

GARCI-GÓMEZ, Miguel.

s.f. "El león reverente del Cantar de Mio Cid", http://mgarci.aas.duke.edu/celestina/MIO-

CID/ENSAYOS/LEON.HTM [consulta: 2/06/2016]

HAWTREE, Laura J.

2011 Wild Animals in roman Epic.

https://ore.exeter.ac.uk/repository/bitstream/handle/10036/3469/Ha wtreeL.pdf?sequence=1 [consulta: 19/04/2016]

HIGHET, Gilbert.

1978 La tradición clásica II. Antonio Alatorre (trad.). México: FCE [1949]. 
HORACIO FLACO, Quinto.

1990 Odas y Épodos. Manuel Fernández-Galiano y Vicente Cristóbal (eds.) y Manuel Fernández-Galiano (trad.). Madrid: Cátedra.

LOVELUCK, Juan.

1967 "Rubén Darío, novelista: El hombre de oro", Asomante, XXIII: 1 (1967), pp. 43-57.

MATA INDURÁIN, Carlos.

1998 "De princesas, rosas e historias sobrenaturales: El arte del cuento en Rubén Darío", en Rubén Darío y el arte de la prosa. Ensayo, retratos y alegorias. Cristóbal Cuevas García (ed.) y Enrique Baena (coord.). Málaga: Publicaciones del Congreso de Literatura Española Contemporánea, pp. 359-371.

MARASSO, Arturo.

1954 Rubén Dario y su creación poética. Buenos Aires: Kapelusz.

POIRIER, Eduardo.

1900 "Carta dirigida a Rubén Darío".

http://alfama.sim.ucm.es/greco/rd-digital.php?pag=10

[consulta: 8/03/2016]

MARINI-PALMIERI, Enrique

1989 "Introducción" a Cuentos modernistas hispano-americanos. Madrid: Castalia, pp.11-41.

PHILIPPS-LÓPEZ, Dolores.

1998 "Rubén Darío y la novela", en Rubén Dario y el arte de la prosa. Ensayo, retratos, alegorías. Cristóbal Cuevas García y Enrique Baena (eds.). Málaga: Publicaciones del Congreso de Literatura Española Contemporánea, pp. 211-225.

RICHMOND, Carolyn.

1990 "La figura del escritor en un cuento clariniano: el romano Vario", en Leopoldo Alas "Clarín", "Vario".... Y varia: Clarín a través de cinco cuentos suyos. Madrid: Orígenes, pp. 17-76.

RoviRA, José Carlos.

2009 "La lección de Darío en la España de 1905: lo clásico como otro origen de la modernidad", CILHA, 10 (11), pp. 128-137.

http://ffyl1.uncu.edu.ar/IMG/pdf/v10n1a10.pdf [consulta: 30/04/2016].

RUIZ SÁNCHEZ, Marcos.

1999 "Paganismo y cristianismo en Rubén Darío. A propósito de $L a$ fiesta de Roma y El hombre de oro", Filología y Lingüística, XXV (2), pp. 23-45.

SUETONIO.

1992 Vidas de los doce césares. II. Rosa Ma Agudo Cubas (trad. y notas). Madrid: Gredos, 1992. 
SuX, Alejandro.

1946 "Rubén Darío visto por Alejandro Sux", Revista Hispánica Moderna, 12 (1), pp. 302-320.

TÁCITO.

1980 Anales. Libros XI-XVI. José L. Moralejo (trad. y notas). Madrid: Gredos. 